\title{
Barriers to and Benefits of the Use of Smart Farming Technologies for Small and Medium Winemakers, Specifically Sensors and Weather Stations: A Pilot Study
}

\author{
Lucie Kaňovská \\ Faculty of Business and Management, Brno University of Technology, Czech Republic
}

\begin{abstract}
Digitization is becoming part of agriculture. Winemakers can use monitoring technologies to map land or control the quality of grapes, and telematics, e.g., in tractors, or use entire autonomous machines. The aim of this paper is to find out the barriers to and benefits of the use of smart farming technologies by small and medium winemakers, specifically sensors and weather stations, which allow the collection of site-specific data for subsequent application in viticulture. Therefore, the pilot study analyses how winemakers in traditional industry are able to employ smart farming technologies (SFT) to gain some benefits and also describe possible barriers. The primary method of data collection was through 27 semistructured interviews with relevant wine industry actors, accessing documents created by SFT providers and an academic literature review. Three groups of actors were researched: 1) 22 winemakers including the Ekovin Association, 2) three SFT providers and, 3) one supplier of hardware for soil and temperature sensors. According to the information of winemakers, it is clear that SFT are used by some of them and they are clearly aware of their benefits, which is also confirmed by SFT providers. The findings revealed that the main STF benefits are adjustment of the product portfolio, savings, consulting and organization of activities. However, respondents also mentioned barriers to SFT implementation, such as low need for information, another source of information, conservative approaches, ignorance of SFT, financial demands, low state support and age of winemakers. The novelty of this paper is in providing an analysis of the issue of SFT, specifically sensors and weather stations, for winemakers from three different perspectives, that of winemakers, suppliers of SFT and HW manufacturer for SFT.
\end{abstract}

\section{Keywords}

Smart farming technologies, precision agriculture, precision viticulture, winemakers, Czech Republic.

Kaňovská, L. (2021) "Barriers to and Benefits of the Use of Smart Farming Technologies for Small and Medium Winemakers, Specifically Sensors and Weather Stations: A Pilot Study", AGRIS on-line Papers in Economics and Informatics, Vol. 13, No. 1, pp. 71-85. ISSN 1804-1930. DOI 10.7160/aol.2021.130106.

\section{Introduction}

As in industry, digitization is also becoming part of agriculture. Precision agriculture (PA) is a relatively new discipline in agronomy. Developed in the mid-1980s, it has been listed among the top ten agricultural enhancements in recent decades (Crookston, 2006). Farmers use smart farming technologies (SFT), which make farming processes more data dependent. Thanks to these technologies, it is possible to increase the accuracy of inputs to crops and soils based on the environmental context and specific needs of the site. The global agricultural industry is constantly seeking to maximize its concerns' economic, environmental and qualitative benefits.
Secondly, modern automation for effective agro-production is still not used by most sectors. Smart technologies have presented new and innovative ways for optimized agriculture via an automated system of environmental parameter monitoring. Viticulture, for example, is a highly delicate process in which mesoclimate and soil conditions are inherent; thus, checks and efficient quality control of the process is essential (Voutos et al., 2018). Four modes of SFT can presently be distinguished in accordance with Fountas et al. (2015): (1) recording and mapping technologies, which collect site-specific data for further application, (2) tractor GPS and associated tools that apply variable rates of inputs as appropriate 
and accurately guide tractors via real-time kinetics, (3) apps and farm management and information systems (FMIS) integrated and linked with mobile devices to offer easier farm monitoring and management, and (4) machines which operate autonomously (e.g., weeding and harvesting robotic systems).

How can SFT help winemakers produce better harvests? Generally, winemakers rely on more advanced weather forecasts, but in the past also on the knowledge of older winemakers, who remembered the weather conditions for each slope of a vineyard. Unfortunately, the latter situation has not been the case for some time due to climate change and/or human intervention. The weather is simply harder to predict than in the past, and winemakers need the most accurate data possible. The solution is a small weather station, which is located in a vineyard and can measure temperature, humidity, precipitation and calculate, for example, a dew point (Průžek, 2019). This data is sent at regular intervals via the network to the server and the winemakers receive a relatively accurate forecast, or just the data measured, on their mobile phone or via the web interface on the computer. The data should be accurate enough to predict impending frosts. Thanks to this technology, winemakers can prevent the growth of basic pathogens with a significantly lower use of chemicals (Prüžek, 2019).

\section{Precision viticulture}

Precision viticulture (PV) is a relatively new discipline, whose development started in the 1990s (Sentesban, 2019). Some scholars use other designations such as smart viticulture or Viticulture 4.0. In this paper precision viticulture (PV) will be used. PV technologies have more recently enjoyed a rapid evolution and superior applicability because of reduced costs, ease of use, and versatility. These innovative solutions' benefits regarding their application is generally in the form of financial savings in crop management, and greater ecological sustainability due to the rationing of chemicals used in farming (Matese and $\mathrm{Di}$ Gennaro, 2015). The fast pace of information communication technologies and geographical science provides for PV huge potential for the advancement of optimized solutions for the dissemination of information. PV therefore strives to utilise the broadest range of observations at hand to outline in high resolution a vineyard's spatial variability. It further seeks to offer suggestions for the improvement of efficiency of management relating to quality, production, and sustainability (Matese and Di Gennaro, 2015).

The implementation of PA techniques into viticulture, i.e., the development of $\mathrm{PV}$, occurred significantly later than was the case in other crops. Research and commercial applications in PV only commenced in the mid-2000s (Santesteban, 2019). The reason for this delayed adoption was not apathy on the part of wine growers, but rather difficulties inherently associated with vineyard characteristics: discontinuous canopy usage and the organization of vines in rows require higher resolution images to distinguish canopy from soil, and superior computing capacity for the management of vineyard spatial information before being used (Matese et al., 2015). Recent technological developments have seen the enhancement of tools to aid in the monitoring and control of many parts of vine growth. Remote and proximal sensing sensors have become substantial resources for the determination of vineyard status, such as water and nutrient availability, plant health and pathogen attacks, or soil conditions.

\section{Smart Farming Technologies in precision viticulture}

SFT used in PV are divided into two main categories. The first one focuses on monitoring technologies, which form the foundation of spatial variability mapping. The second discusses technologies used in the provision of site-specific agronomic inputs, classified as variable rate technologies (VRTs) and "agbot" systems (Matese and Di Gennaro, 2015). The acquisition of the maximum possible amount of georeferenced information within the vineyard is the primary goal of the monitoring process. A broad range of sensors seeking to monitor various parameters which characterize the plant growth environment are utilised in PV for remote and proximal monitoring of geolocated data. The three systems employed most frequently in remote sensing are satellites, aircraft, and unmanned aerial vehicles (UAVs), each using different application methods and sensors (Matese and Di Gennaro, 2015). VRT in PV permits agronomic management to be differentiated and the inputs dosed in terms of time and space. Software programs within the technology have the ability to combine the positional information, obtained by a GPS module, with prescription maps created for each specific operation (Escolá et al., 2007). The application of agronomic inputs is therefore no longer derived as average quantities per hectare, but instead according to the actual requirements of the vines ascertained 
from the vineyard heterogeneity. Automation technologies are used in modern agricultural machinery to control movement within the vineyard, relating to velocity and direction of travel and steering angle, and further to oversee agronomic operations. An automatic guidance system based on the use of GPS and proximity sensors is viable due to the presence of advanced board technology (Vieri et al, 2013). This article focuses only on the first area (monitoring technologies, which form the foundation of spatial variability mapping) and is considered from three different perspectives, that of winemakers, suppliers of SFT and HW manufacturers for SFT.

The use of robotics in PV currently remains at the prototype stage, but a great deal of these projects is already close to completion, with some already available on the market (Matese and Di Gennaro, 2015). However, there are some current examples of robot implementation. Château Clerc Milon winery from Bordeaux, France, is one example of where a robot has been used, its value coming from its collecting of data directly at the vineyard and this data's subsequent evaluation, which is then easily transferred to the winemaker's computer or mobile phone. Moreover, it can assist with general farm work, such as the spraying or pruning of shrubs. The Spanish VineScout robot project is another example of robotic data collection of vine growth. It was granted European Union funding and commenced in August 2019. These are not breakthrough technologies unseen in other sectors, but their existence is proof that very traditional industries, such as viticulture, are beginning to deploy them (Strouhal, 2020). In Napa Valley, California, at the Palmaz winery, big data is similarly used to produce the most optimal bottle of wine, according to owner Christian Palmaz. His Vigor system (conjunction with Filics software) combines sensors, probes and X-rays in the collection of millions of data units, which subsequently serve as an alert to various diseases or determine optimal harvest time and grape storage, as well as helping to produce great quality wine (Strouhal, 2020).

\section{Smart Farming Technologies in precision viticulture in the Czech Republic}

Similar technologies have also already been implemented by some Czech SFT providers, e.g., by the Czech startup Agdata, which is building an information platform combining IoT sensors and other data from farms as well as from the fields themselves. It is not focused directly on viticulture, but it can be also used for winemakers (Strouhal, 2020). AG data offers everything for PA in one system, namely business management, sensors, machine monitoring, satellite imaging, legal records, leases. Its system allows easy planning of crops, field work, property management or, for example, automatic recording of activities. It draws important data from the agricultural registers of the Farmer's Portal and ČUZK and is closely connected to many physical devices such as GPS or wireless sensors, which provide you with real-time telematics of your machines or information about warehouse conditions (Agdata, 2020). Clever Farm has developed an application that offers all the principles of modern agriculture in one. Their platform delivers a sustainable, cost-effective and automated way of farming. The company focuses on four areas, namely: agroevidence, sensors, PA and soil registration. Its products can be applied to various parts of the world, from small family farms to large companies owning tens of thousands of hectares (Cleverfarm, 2020). This company provides a soil sensor, which measures the humidity and temperature at the depth of insertion of the sensor. A moisture absorption sensor was used to measure the water potential of the soil, which eliminates influences that could skew the measurement and does not require calibration on the soil type and chemical composition. The sensor will help to optimize irrigation and determine the appropriate planting time. The sensor is either on a pole or on buried wires (Cleverfarm, 2020).

The Czech "Smart Vineyard" project (Chytrá vinice) uses small-sized, new generation weather stations which record temperature, humidity and rainfall data. As a result, they provide winemakers with information on temperature, dew points, precipitation and local conditions relating to the occurrence of the pathogens Vine fungi, Vine powdery mildew and Botrytis cinerea. All information is displayed on the winemaker's computer or directly on their smartphone. 31 winemakers and 78 smart vineyards are involved in the project, with the equipment involved already on the market for four seasons (Chytrá vinice, 2020). Another new interesting project is DynaCrop API, which is being developed by the World from Space company. It can help to obtain instant access to agriculture related information for any location in the world and company products can increase the field yields and reduce inputs to save money for its customers. 
The company provides services such as a single observation map (anytime), time series graph, field zones, smi (DynaCrop, 2020).

There are also other companies which are more local providing SFT, such as AMET - sdružení Litschmann \& Suchý (AMET), which map pests, temperatures, precipitation and prepares information from weather stations and other information (Amet, 2020). Mr. Litschmann is the author of many articles published in various magazines and proceedings, which are mainly focused on the processing of information from weather stations, such as wind conditions in wine regions of the Czech Republic in 2019.Concurrently, some wine associations, such as Ekovín, are enthusiastic advocates of using data from weather stations as well. Ekovín brings together winemakers and winegrowers engaged in integrated production and organic production of grapes and wine. It publishes weekly on its website and sends its members an email with a Monitoring Report on the occurrence of harmful organisms in vines in South Moravia, which provides important information about possible pests, as well as temperature and precipitation (Ekovín, 2020).

iNELS, a product of ELKO EP, has existed since 2007, when it was one of the first pioneers in the Czech Republic to develop and manufacture intelligent wiring for houses and buildings called Smart Home \& Building Solutions (iNels, 2020). In agriculture its products can be used on farms, greenhouses, apiaries or in forests and pastures. On farms, SFT can safely monitor via motion sensors and a camera system, as well as significantly help save energy through lighting control. In fields, sensors and weather stations can monitor the status of conditions in production areas. Products provide information on temperature, air and soil humidity, precipitation, wind strength and direction, which can be displayed via applications on a computer or smartphone (iNels, 2020).

There are a large number of smart agriculture platforms abroad, such as The SmartAgriFood Accelerator, which is supporting SMEs developing smart services and apps to be addressed in the agrifood sector or Smart Farming Thematic Network, which is open to farmers, SFT solution providers or researchers.

\section{Related works}

In order to improve comprehension of the relevance of current technological progress in European farming systems, 287 farmers were surveyed in seven EU countries and in four cropping systems. Of the farmers interviewed, around 50\% had utilised SFT and 50\% had not. Out of 287 farmers, 66 were wine growers, 24 of whom were SFT adopters and 42 were non-adopters. Farm size positively correlated with adopter numbers, and adopters in arablecropping systems outnumbered those in tree crop and vineyard farming (Kernecker et al., 2020). López-Leyva et al. (2019) presented the design and field tests of a system to remotely monitor environmental variables in a vineyard in the Guadalupe Valley, Mexico, which was done with early-adopters to find out the performance of the prototype. Dorofeeva et al. (2019) mention that the systems of parallel driving, informatization and monitoring, mapping of yield and differential fertilization are implemented in precision farming in Russia. The costs of fuel, seeds, fertilizers, and chemical means of protecting crops are reduced by using these technologies. Similarly, Caffaro and Cavallo (2019) also found a low uptake of both investigated technologies a) SFT Type 1, which involves technologies investigated, the management information systems, such as drones, sensors for data acquisition and automatic download, and agricultural apps and b) SFT Type 2, which involves in-field advanced working tools technologies such as agricultural robots and autonomous machines, and tractors equipped with CAN-bus, which is an electronic system connecting components of the tractor (engine, transmission, hydraulic system), implements (seeder, fertilizer spreader, etc.), and sensors (typically GPS positioning systems), even though those who participated in the research stated that in daily life they used ICT regularly. It is therefore crucial that the ICT options most useful to farmers are identified in order to be able to convey how these targeted agricultural interventions can benefit their operations. This will be crucial in closing the gap between those farmers who willingly use ICT in their daily lives but are more reticent about using SFTs in their professional work. Martini et al. (2020) present a systematic mapping of studies that use prediction and context awareness in agriculture. Their findings showed that $35.7 \%$ of the studies used one or more prediction techniques, $45.2 \%$ used image processing through pictures of cameras to get information regarding planting. They found 23 sensors with different functionalities in agriculture.

\section{Drivers, benefits and barriers of SFT}

The main drivers for the implementation of precision farming not only in Russia, but throughout the world, are maximizing 
the harvest, financial benefits, minimizing capital investments and minimizing the impact on the environment (Dorofeeva et al., 2019). However, winemakers' general views on SFT and their experience with them is a key driver in whether they believe they need to use weather stations. Kernecker et al. (2020) present the five most important reasons for the use of SFT in agriculture as follows: SFT are helpful for agriculture; SFT improve on previous tools; SFT improve work processes and workload; SFT use sees an increase in productivity and work comfort. New technologies ensure to lower production costs between 20 and $30 \%$ which would be helpful for winemakers (Proffitt, 2015). Cost reduction is mainly coming from optimising the utilisation of water, fertilizers, fungicides and also from working efficiently in the vineyard (Advanced Technologies for Industry, 2017). The claim that SFT would reduce a farm's impact on the environment, that SFT can improve farm intake and decrease farm pollution was, however, the most disputed by farmers (Kernecker et al., 2020). GPS-related technologies are most significant to arable farming; mapping and recording tools, which are able to track weather events, for example, have greater worth in horticulture and viticulture, where yields and income per hectare are more impacted upon by microclimate or plant diseases (Kernecker et al., 2020).

Kernecker et al. (2020) also note that the adoption of STF may be inhibited by certain factors. Reasons for not adopting SFT: high investment costs; too complex to use; inappropriate technology in relation to the farm context and size; the added benefits of SFT are unclear, a situation not improved by live demonstrations of SFT use with a neutral advocate not being accessible to farmers. Barriers for those who do adopt SFT are as follows: high investment costs; difficulty of interpreting data; no interoperability between devices and a lack of precision; added benefits are unclear and neutral advice is again lacking. In addition, it was stated by both farmers and experts from all sectors across Europe that the cost-benefit and added value were not clear and that insufficient infrastructure, such as weak broadband connectivity, also prevented SFT adoption, alongside a lack of current information and high costs, is an important determiner of access to SFT (Kernecker et al., 2020).

Current literature available focuses mainly on arable farming and respective technologies (e.g., GNSS based technologies), which subsequently and generally serves larger farms in north-western EU nations better than smaller farms in other states (Kernecker et al., 2020). Consequently, this necessitates an increased research focus on small farmers, such as winegrowers, from regions beyond that of the north-western EU. As Kerneker's et al. (2020) comment, mapping and recording technologies are the more relevant SFT type for orchards and vineyards. Therefore, the research was focused on SFT which can be used in viticulture. The aim of this paper is to find out the barriers to and benefits of the use of smart farming technologies by small and medium winemakers, specifically sensors and weather stations, which allow the collection of site-specific data for subsequent application in viticulture. In order to fulfil the aim of the paper, three research questions have been researched:

RQ1: Do small and medium winemakers use SFT, specifically sensors and weather stations?

RQ2: What are the benefits of the use of SFT by small and medium winemakers, specifically sensors and weather stations?

RQ3: What are the barriers to the use of SFT by small and medium winemakers, specifically sensors and weather stations?

To find out the answers to these research questions, a combination of surveys of winemakers, SFT providers in viticulture and supplier of hardware for sensors was used, so that the issue was processed from complex perspectives.

\section{Materials and methods}

Manufacturers combine servitization and digitisation, but academic research in this field has only taken place quite recently (Raddats et al, 2019). Even among farmers, SFT are beginning to be used successfully and, in some regions and areas, SFT are almost a matter of course. However, in general, agriculture is still perceived as a traditional and rather conservative sector. Agriculture is the oldest sector of the economy and after a period of consolidation of technologies from 1990 to 2000, it has experienced a spectacular evolution under so-called Precision Agriculture (PA) (Caffaro and Cavallo, 2019). Technological innovations are changing mechanisation in agriculture. The introduction of modern ICT in the agricultural sector is necessitated by the ever-growing demand for food and farm products. The agricultural industry is not the origin of Industry 4.0, as it is considered 
one of the least digitized industries overall, but the potential of advanced manufacturing methods has been recognized across all sectors (Gandhi et al., 2016). However, no research has focused on the use of SFT, specifically sensors and weather stations, by winemakers from complex perspective, i.e., from the point of view of winemakers, suppliers of SFT or HW manufacturers for SFT.

To learn more about SFT used by winemakers, the empirical part of the research included a) interviews with winemakers, b) interviews with SFT providers, including those in winemaking and c) interviews with HW manufacturers of SFT. To find out more about this topic, a combination of surveys was used, so that the issue was processed from complex perspectives. Surveys were conducted in the form of semi-structured interviews. The areas of interview issues were partially inspired by the previous research of the author of this paper, which was held in small and medium electrotechnical companies in 2017-2018. The interviews with winemakers targeted the following areas: basic information about winery; type of SFT; the reasons for the commencement of SFT provision; the benefits gained from SFT; possible barriers to implement SFT and using the data gained from SFT. The interviews with SFT providers and interviews with HW manufacturers for SFT targeted the following areas: type of SFT provided for winemakers or for SFT providers; the length and manner of SFT provision; customer segmentation; customer perception of SFT; the reasons for commencing SFT provision; the benefits gained from SFT; barriers connected to SFT provision; gathering and usage of the data gained from SFT; specifics of the Czech market; collaboration with other firms in SFT development and future plans. For this paper, only relevant areas from interviews related to the aim of the paper (description of winemakers and SFT providers, the benefits gained from SFT and possible barriers to implementation of SFT) were selected and described.

\section{Sample and data collection}

The Czech Republic has two wine regions, Moravia and Bohemia, divided into six subregions. There are 383 wine villages and 18067.93 hectares in 1,313 vineyards. These are managed by 18,399 growers. Most vineyards (96\%) are located in Moravia, with the remaining $4 \%$ in Bohemia. Of the total area, $70 \%$ is planted with white grape varieties. There are over 1000 registered wineries, from large companies to small family businesses (Wine regions of the Czech Republic, 2019). The largest expanse of vineyards is in the Velkopavlovická Wine sub-region. The fertile lowlands, which stretch from Brno to Židlochovice, Hustopeče, Velké Bílovice and Velké Pavlovice, belong among the sunniest places of the Czech Republic (Wine regions of the Czech Republic, 2019). According to the Czech Statistical Office, the consumption of grape wine (fruit wine is not included) has increased by almost half since 1989 . From the original 11.3 litres per person in 1989 , it climbed to 16.9 litres per person in 2016. According to the Winegrowers' Association, wine production in the Czech Republic has fluctuated around $600,000 \mathrm{hl}$ per year in recent years. Consumption is above 2.1 million hl. About three quarters of the wine drunk is therefore imported to us (Nevyhoštěný and Chripák, 2019).

To answer the research questions, the surveys were prepared in order to map complex views, namely those of SFT providers to the winery, suppliers of HW for SFT providers and winemakers where SFT adopters and SFT non-adopters were included. The respondents were recruited from owners and top managers (in-depth interviews with SFT providers and HW suppliers) and from owners or managers (interviews with winemakers). The primary method of data collection was via 26 semi-structured interviews with relevant wine industry actors, accessing documents created by SFT providers and an academic literature review. Three groups of actors were researched: 1) 22 winemakers including the Ekovín Association of ecological wine growers and winemakers, 2) Three SFT providers (AG data, Clever Farm and Chytrá vinice - Smart vineyard) and 3) One supplier of hardware for soil and temperature sensors (ELKO EP). The sample covers all of the three actor types operating in this market.

\section{Interviews with winemakers}

For this pilot study examining the use of smart products in viticulture, the small and medium-sized winemakers were only from the Velkopavlovická Wine subregion, which is one of the six wine regions in the Czech Republic. Those in the small winery category produce up to 50,000 litres a year; those in the medium viticulture category produce 5,000 to 250,000 litres a year; those in the large winery category produce over 250,000 litres a year (Vinařství roku, 2020). Respondents from viticulture were selected on the basis of purposive sampling according to the list of members of the Union of Winemakers 
of the Czech Republic. In addition, snowball sampling (Coleman, 1958) was used, when the process began with the suppliers of SFT for viticulture, who suggested some winemakers who were already using SFT. This type of sampling is cost and time efficient (Kemper et al., 2003). Interviews lasted 20 to 30 minutes and were held in September and October 2020. The interviews were done mainly via online calls through Skype or Google Meet and in ten cases via email when the list of questions was sent directly to the winemakers. The total number of winemakers included in the survey is 22 , where nine winemakers were SFT adopters, 12 winemakers were SFT non-adopters and one was the Ekovín Association.

Interviews with SFT providers and SFT suppliers of hardware

In order to broaden the view of the issue, the most important SFT providers (including SFT for viticulture) in the Czech Republic were also contacted. These included CleverFarm, Agdata and Chytrá vinice (Smart vineyard), who were selected after a thorough website study. Even according to the winemakers, themselves, who were participants in the research, all the main actors of SFT provision in this business were addressed in the research. Also, one supplier of hardware for soil and temperature sensors (ELKO EP) was included in the research. Interviews lasted 30 to 60 minutes and were held in October 2020. The interviews were done during online calls via Skype or Google Meet.

\section{Data analysis}

Interviews were mainly recorded and transcribed. About 14 categories related to benefits of SFT were extracted from the initial research, of which an analysis was made in order to ascertain which were similar and which were different. Reduction of the number of codes then took place, resulting in the number of first-order categories becoming eight. Aggregate themes of a more abstract nature were then determined through analysis of the first-order categories. This process yielded three agglomerated themes labeled Savings, Consulting and Organization of activities. The final coding structure is shown in Table 3. The benefits of SFT by winemakers and for barriers related to SFT by SFT providers and winemakers was subjected to an identical procedure (Table 2, Table 4 and Table 5). As qualitative case research is sensitive to researchers' subjective explanations, some peer consultation was needed to avoid researcher bias and to ensure greater objectivity in the study. A rich set of direct interview quotations to demonstrate interpretations was added to support the transparency and conformability of the findings.

\section{Results and discussion}

The pilot study analyses how winemakers in traditional industry are able to employ SFT to gain some benefits or how they struggle to implement them. The findings to RQ1 - RQ3 are presented below along with some quotes which help to illustrate the findings.

RQ1: Do small and medium winemakers use SFT, specifically sensors and weather stations?

The total number of winemakers included in the survey is 21 , where nine winemakers (43\%) were SFT adopters and 12 winemakers (57\%) were SFT non-adopters (see Table 2). However, Ekovín also prepares the documents for the Monitoring Report for their members. This document is sent to them weekly and it is also uploaded onto the Ekovín website. The Monitoring Report is prepared by Ekovín on the basis of its own experts and some member companies. Ekovín also cooperates with CleverFarm, Chytrá vinice (Smart Vineyard) and AMET.

\begin{tabular}{|l|c|c|c|}
\hline & $\begin{array}{c}\text { Small } \\
\text { winery }\end{array}$ & $\begin{array}{c}\text { Medium } \\
\text { winery }\end{array}$ & Total \\
\hline SFT Adopters & 4 & 5 & 9 \\
\hline SFT Non-adopters & 8 & 4 & 12 \\
\hline Total & 12 & 9 & 21 \\
\hline
\end{tabular}

Source: Author

Table 1. SFT adopters and SFT non-adopters which participated in the surveys.

Of the SFT Adopters, four are small winemakers and five are medium-sized winemakers, which is an almost identical result. A bigger difference can be seen in SFT non-adopters, where eight of them are small winemakers and four are medium-sized winemakers (see Table 1). SFT providers who participated in the research offer farmers (including winemakers) the following products: a) IoT sensors and weather stations that monitor irrigation, pests, precipitation, temperature, leaf wetting. Based on mathematical models, they predict development and inform users about the status of pests in three colors: green - no problem; orange - checking required; and red - necessary intervention of spraying, B) satellite data - biophysical parameters from the satellite, which show where the largest yield is and divide the land into five zones to manage the fertilization process, 
c) agroevidence - records of fertilizers, sprays, seeds, which are a necessary legislative component and d) records of land and lease agreements. According to SFT providers, winemakers use area a) and c) the most, with a predominance of sensors and weather stations.

According to SFT providers, their customers are from all categories of winemakers - from micro winemakers to large wineries. But their typical customer is an older winemaker who hands over his winery to a younger one, such as a father and son, or a young agronomist at a larger winery who is about 30 - 40 years old. These younger winemakers have a closer relationship to SFT. However, it's not always about age, even older winemakers choose to use SFT. However, all SFT providers clearly agree that in recent years the situation has shifted greatly (thanks to gradual generational change) and improved for SFT, and it is only a matter of time before most winemakers will perceive the benefits of these SFT.

"Our service can be used for 12/24/36 months and then it is possible to terminate it, but it hasn't happened yet."

"SFT have been an important topic in the world for a long time, there is less interest in them in the Czech Republic. However, even here they have become a sexy topic."

"Czech agriculture is well modernized, such as modern tractors, machines, but there is a lack of digitization and interconnection of systems at farmers. Several of the largest agribusinesses have a digitized agenda (such as fuel), but there is a lack of connection between individual agendas. Small businesses have nothing, sometimes they have software for wages, agricultural records, such as fertilizer records, but nothing complex."

To sum it up, winemakers are increasingly starting to use SFT, especially sensors and weather stations in their wineries. SFT adopters are rather younger winemakers (30 - 40 years) who have a closer relationship with SFT and have information about their use and possible benefits. Confirmation of interest in SFT is also shown by Ekovín activity, which regularly informs its members on a weekly basis about environmental monitoring.

RQ2: What are the benefits of the use of SFT by small and medium winemakers, specifically sensors and weather stations?

Winemakers perceive the main benefits of using sensors and weather stations in the following items: time savings, financial savings and adjustment of the product portfolio in line with changing climatic conditions. The main two benefits are savings and consulting. The final coding structure is shown in Table 2.

\begin{tabular}{|l|l|c|}
\hline \multicolumn{1}{|c|}{ First-order categories } & & Aggregate themes \\
\hline Time savings & $\rightarrow$ & Savings \\
\hline Financial Savings & $\rightarrow$ & \\
\cline { 1 - 1 } $\begin{array}{l}\text { Adjustment of the product } \\
\text { portfolio in response } \\
\text { to changing climatic conditions }\end{array}$ & $\rightarrow$ & $\begin{array}{c}\text { Adjustment } \\
\text { of the product portfolio }\end{array}$ \\
\hline
\end{tabular}

Source: Author

Table 2. STF benefit categories by winemakers.

According to STF providers and HW supplier, the benefits of using sensors and weather stations were the following: saving time; saving petrol; saving costs of fertilization; irrigation; spraying; saving personnel; advice on what to do; which pests to target; help with drought; when and how much to water. The benefits were additionally seen in the overview of the use of one system, where all the important information will be held. The main three benefits are savings, consulting and organization of activities. The final coding structure is shown in Table 3.

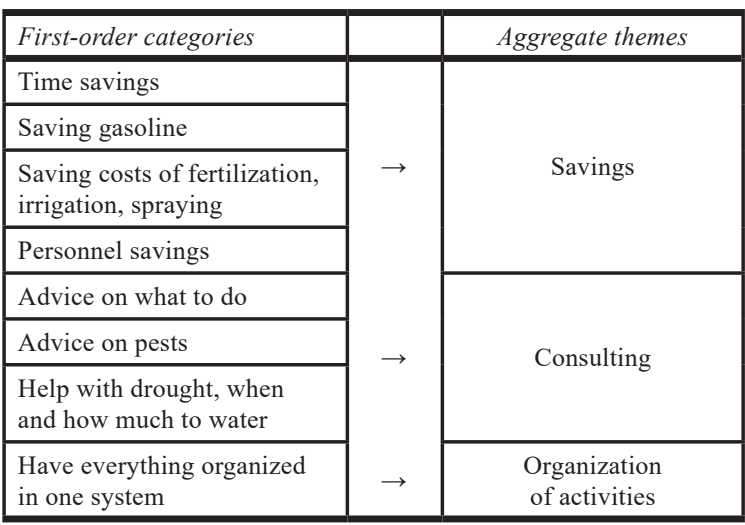

Source: Author

Table 3. STF benefit categories by STF providers and HW supplier.

CleverFarm also features case studies on its website that show financial savings when using their SFT. According to them, it is very suitable for helping potential customers to realistically understand what their solution can bring them.

"Smart technologies are currently key for us in deciding on economic interventions, which affects economic efficiency. According to the information, the use of SFT requires a combination of experience / knowledge and quality data from these technologies." 
"For micro-winemakers, it is certainly a great advantage of the information obtained from the weather station, whether it is necessary to go to the vineyard today or not."

"For large wineries, the advantage is definitely some help with the organization of work, when they have large areas of vineyards. The solution will advise them where they need it today and where tomorrow."

"Thanks to SFT, we are able to adjust the planting of suitable varieties, based on temperature information within the year."

"Declining rainfall and climate change are forcing winemakers to be effective. There is also state pressure starting to save water and sprays."

RQ3: What are the barriers to the use of SFT by small and medium winemakers, specifically sensors and weather stations?

Winemakers perceive the main barriers to using sensors and weather stations in the following items: low need for information; traditional approaches; ignorance of SFT, which means no awareness of SFT, no experience and ignorance of SFT benefits; financial demands and another source of information. The final coding structure is shown in Table 4.

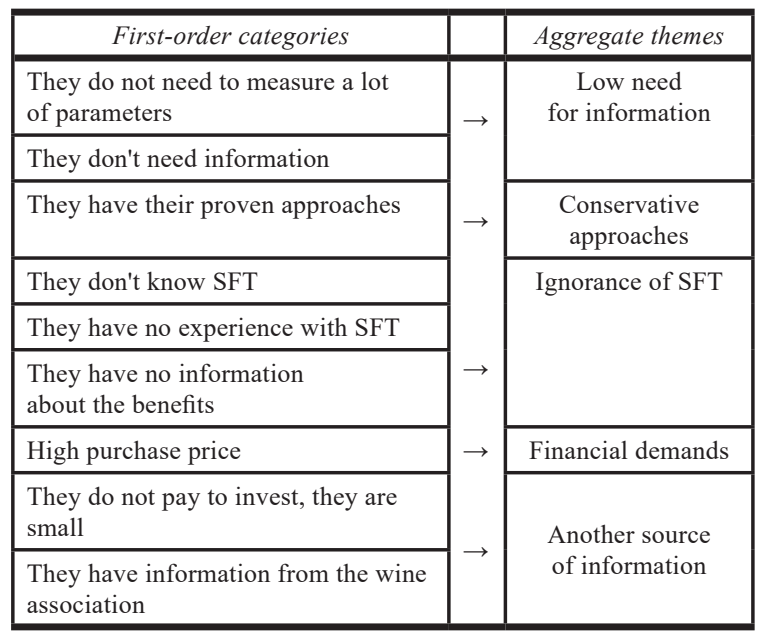

Source: Author

Table 4. Categories of STF barriers by winemakers.

"We do not use any weather stations. We only have automatic shears for cutting the vineyard."

"We don't have a weather station, but we considered a combine with telematics, but the price discouraged us. But maybe we will try to look at a subsidy if something could not be used."

"We do not use our online weather station. If we need to know something about, for example, the amount of precipitation, temperatures and the like, then we will find out the information from a farmer's neighbor who uses the weather station. Unfortunately, I don't even know anyone who should have a weather station and actively use the data. Only someone who has hundreds of hectares of vineyards and agronomists does it."

"We do not use SFT because it is not worth investing in them. We make wine either for fun or just as extra income."

"This year, I take over the winery from my grandfather, which is why we are currently behind the times with smart technologies."

"We don't use any technologies of this type, we take care of everything ourselves, although it is more laborious and demanding, but it is still sufficient for our production."

"Many of our well-known winemakers are members of the Ekovín association, just like us. Every week, Ekovin sends a monitoring report with the currentmeteorological situation and forecast for the coming days, then some possible development of pests and other information."

STF providers and HW supplier perceive as the main barriers to using sensors and weather stations the following ones: conservative approaches; age of winemakers; ignorance of SFT; financial demands and low state support. The final coding structure is shown in Table 5.

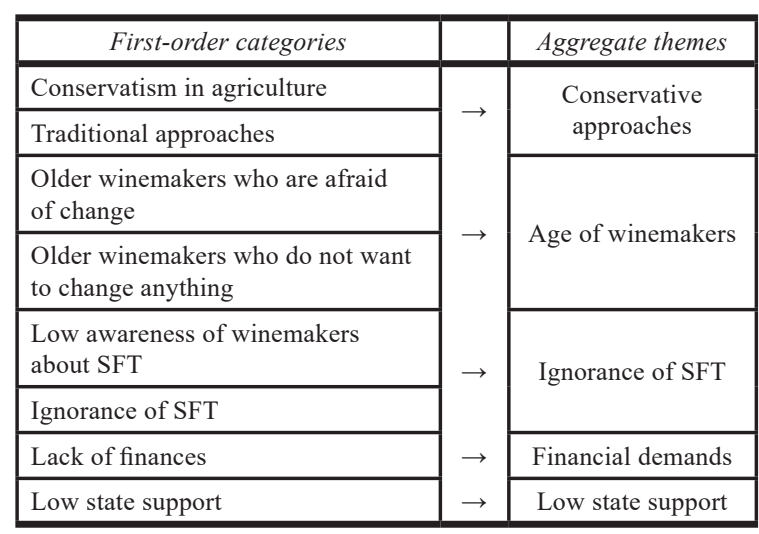

Source: Author

Table 5. Categories of STF barriers by STF providers and HW supplier.

"They've been doing it for 100 years, so they won't change it anymore."

"They often say - I'd rather just go there..."

"Farmers are very conservative and do not want 
much change, especially those older winemakers. But the younger ones are already starting to ask and use SFT. When they get acquainted with SFT, they are excited and want to use them."

\section{Theoretical implications}

The present pilot study investigated how SFT, specifically sensors and weather stations, are used by small and medium winemakers. The results showed that winemakers are starting to use SFT and see the benefits in them. With regards to the Food \& Beverage sector, particularly if the wine industry is taken into account, many scholars pointed out the dynamism and complexity of global markets (Mariani et al., 2012). Globalisation has boosted competition in wine markets (Giuliani et al., 2011) and firms are engaged to face the effects of globalisation and opportunities in new markets such as Chile, South Africa, Australia and China (Spadoni et al., 2019). It is SFT that can help winemakers succeed in this increasingly competitive market, thanks mainly to the financial savings that SFT offers. The study added a novel contribution to previous knowledge on typical SFT benefits and SFT barriers by small and medium winemakers, STF providers and HW supplier. The main STF benefits in viticulture perceived by the respondents are shown in Figure 1 and main SFT barriers are shown in Figure 2.

The main STF benefits perceived by the respondents are adjustment of the product portfolio, savings (of time, people and money), consulting and organization of activities. There are savings as mutual STF benefits in Figure 1. The advantages of savings, such as saving in time, human resources and money, in gasoline, fertilization, irrigation, and spraying were established by the pilot study.
Caffaro and Cavallo (2019) noted that SFTs contribute to the provision of vast ecological benefits such as natural resources being adopted in a more efficient manner of a decrease in nutrient and pesticide usage. The study concurred with these findings. PA or PV translates into the specific areas of each field being assessed as a singular not collective entity and the levels of fertilizer, phytochemicals and/or water application being appropriately altered as a result. (Srinivasan, 2006). When used effectively, this targeted site management can improve the efficiency of agricultural inputs and lead to reduced costs and enhanced benefits. (Yost et al., 2017).

On the other hand, the main STF barriers mentioned by the respondents are low need for information, another source of information, conservative approaches, ignorance of SFT, financial demands, low state support and age of winemakers. There are conservative approaches, ignorance of SFT and financial demands as mutual STF barriers in Figure 2. Pejorative costs are the most common barriers to SFT adoption (Rogers 2003), a consistent trend many papers have noted (e.g., Paustian and Theuvsen 2017; Long et al. 2016). The price of sensors and weather stations are, however, falling, meaning a more important barrier is an adherence to traditional winemaking approaches and a lack of knowledge of SFT (see Table 4, Table 5 and Figure 2). Past papers on this topic noted a low uptake of SFT use, quite frequently accompanied by ostensibly illogical and wasteful actions on the part of farmers (Caffaro and Cavallo, 2019). Some users, for instance, adopted SFTs with success and tangible benefits, but still returned to more conventional forms of farming (e.g., Sneddon et al., 2011; Cullen et al., 2013).

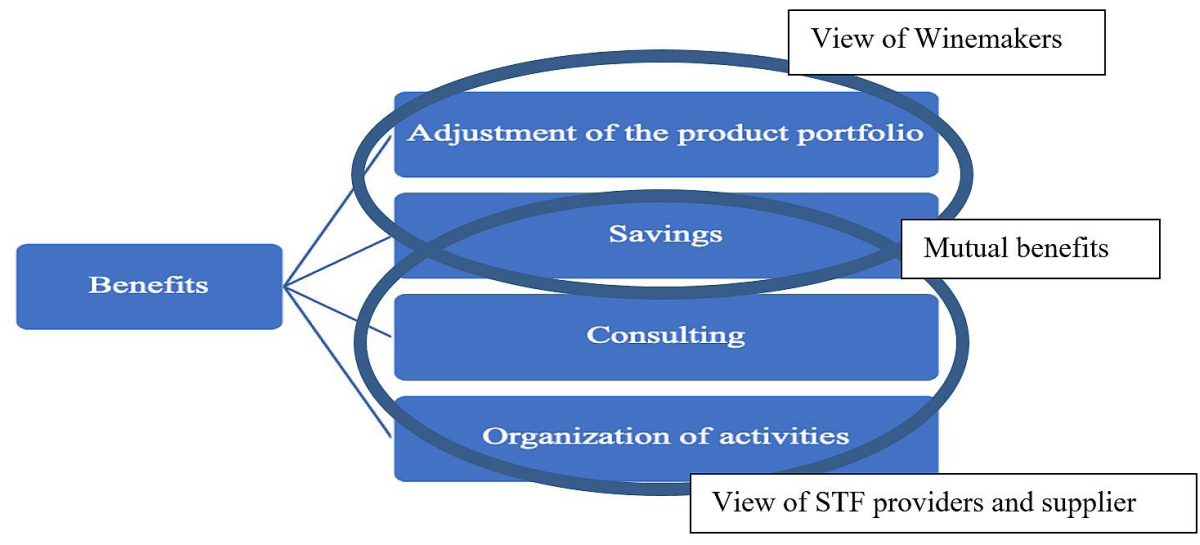

Source: Author

Figure 1. SFT benefits for winemakers, STF providers and HW suppliers. 
Previous research (e.g., Kernecker et al., 2020, Maffioli et al., 2013) have shown that a lack of information on existing innovative technologies as well as individual and impartial advisory services for farmers is a barrier to the widespread uptake of SFT across Europe, as confirmed by the pilot study. In particular, farmers called for independent private advice (Kernecker et al., 2020). Thus, targeted policies and support are recommended for better awareness of SFT (Knuth and Knierim, 2016). Farmers generally consider peer-to-peer communication to be an important source of information and regret the lack of impartial advice. This suggests that if the development and dissemination of the SFT needs to be improved, differences in agricultural structures and farming systems across Europe need to be considered (Kernecker et al., 2020). The low absorption of SFT was mentioned by Caffaro and Cavallo (2019), which is especially evident in older winemakers, respondents to the pilot study, who are used to their traditional practices and do not want to change anything about them. Further technological innovations may enable the smoother integration of reliable smart tools, product delineation and traditions within one agricultural system (Bernetti et al., 2006). Companies are currently wrestling with this balance between convention and technology, trying to keep a brand identity forged from long standing traditional values, while attempting to utilise SFT to get and stay ahead of their competitors (Vrontis et al., 2016).

While all farmers generally believe SFT to be useful for agriculture and broadly expect SFT to continue in terms of specific farm challenges, farmers are less convinced of the potential of SFT (Kernecker et al., 2020). Significantly, both adopting and non-adopting groups are hesitant about adopting SFTs, thus adopters are rather disappointed with the SFT they have experienced and non-adopting because they do not believe that appropriate technologies are available and easy to access (Kernecker et al., 2020).

\section{Managerial implications}

One of the advantages is certainly the selection of suitable biotypes or even new varieties for wine soil efficiently and with sufficient accuracy (Voutes et al., 2018), thanks to the information obtained from sensors and weather stations. However, it is necessary to acquire this data first and be able to process it and use it for further strategic steps. In order for such technologies to be more widely taken on there are challenges to be addressed in terms of not only further necessary exploration of these modern systems, but most predominantly about whether farm workers can be trained up into technicians with the ability to both comprehend and use them (Matese and Di Gennaro, 2015). Furthermore, the study investigated this issue in the Czech Republic, where the winemaking tradition is long, and many wineries have received good ratings. Many young winemakers are also starting to get ahead and try to differentiate themselves from traditional winemakers with their methods of cultivation, processing, distribution and promotion. As Dressler and Paunovic (2020) mention, wine regions in the "old world" countries like Germany need to innovate production practices in order to stay competitive in the world wine market.

Overall, consistent with previous studies performed in different countries (e.g., Kernecker et al., 2020; Caffaro and Cavallo, 2019), research results mapping the use of SFT by small and mediumsized wine growers have shown that interest in SFT among winegrowers is growing every

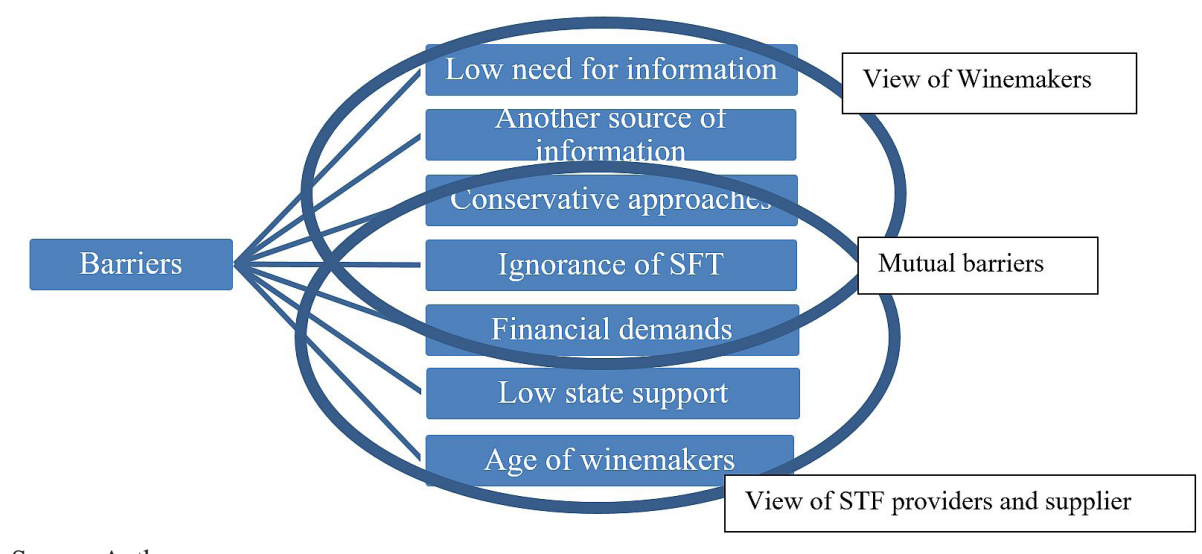

Source: Author

Figure 2. SFT barriers for winemakers, STF providers and HW suppliers. 
year, thanks to the rejuvenation of winegrowers and the ever faster development and implementation of SFT into daily life. However, it is necessary to inform winemakers about these SFTs, including sensors and weather stations, their benefits and the use of the data obtained. Events for winemakers, wine association websites, wine conferences and exhibitions, articles in wine magazines and other wine-oriented activities are ideal. It is important to build a community of enthusiastic SFT adopters. However, personal recommendations are still very important. A good experience of a fellow winemaker who informs others about the benefits and what SFT specifically brought them is still the best advertisement even in today's digital age. This is even more important in traditional industries, where wineries still belong. A very similar situation to viticulture is beginning to be hop growers, where some SFT providers see research potential and are starting to direct their SFTs to them more and more.

Farmers will increasingly operate as managers and supervisors of machinery rather than actually working in the field. Given that the next farming generation are "sons of the internet", they are predicted to naturally adopt SFT (experts from industry) (Kernecker et al., 2020). Knowledge in the field of information and communication technologies has become an essential condition for the success of managers in all areas of economic activity (Hallová et al., 2017). For winemakers, the opportunity is to streamline work processes using network machines. The processes that take place during the alcohol fermentation phase can be controlled and monitored (Průžek, 2019). It is possible to influence any end product in monitoring key indicators in production and using a standardized process, so in wine production it is possible to help by standardizing, digitizing documentation and using barcodes, QR codes or RFID technologies. This allows the process to be monitored at each stage of wine production and the resulting quality be influenced (Průžek, 2019).

\section{Limitations of the paper}

There are two main areas of limits in this paper. Firstly, due to the very small sample of winemakers from only one wine region, this research cannot represent the general population of winemakers. Therefore, this pilot study cannot account for the results, because it is not a representative selection, but the study maps this issue of the use of SFT in viticulture and shows SFT benefits and SFT barriers. Therefore, it would certainly be very interesting to address a larger number of winemakers and verify the information obtained from the first interviews and further deepen this issue. Secondly, the process of coding the information obtained from research to identify key categories and topics was performed primarily by the author of the article. Then there was a consultation of categories and topics with a colleague, but it is still nonetheless very subjective.

\section{Conclusion}

This Third Green Revolution is imposing itself across the agricultural world via the combined application of ICT solutions such as precision equipment, sensors and actuators, Big Data, the Internet of Things (IoT), geo-positioning systems, Unmanned Aerial Vehicles (UAVs, drones), robotics, etc. (Smart Akis, 2020). This paper contributes to better understanding the use of SFT in viticulture, especially by small and medium winemakers. SFT, which is the most recent wave of innovations, promises to improve farming by responding to economic, ecological, and social challenges and thereby sustainably develop agriculture throughout Europe (Kernecker et al., 2020).

According to the information of winemakers, it is clear that SFT are used by some of them. Winemakers are clearly aware of their benefits, which is also confirmed by SFT providers. The findings revealed that the main STF benefits are adjustment of the product portfolio, savings (of time, people and money), consulting and organization of activities. However, respondents also mentioned barriers to SFT implementation, such as low need for information, another source of information, conservative approaches, ignorance of SFT, financial demands, low state support and age of winemakers. There are savings as mutual STF benefits and conservative approaches, ignorance of SFT and financial demands as mutual STF barriers perceived by respondents. The findings will be confirmed by further investigations by more winemakers. Digitization therefore offers great potential for improvement in this area and can contribute to a better use of limited resources. For winemakers themselves, the use of SFT can bring many aforementioned benefits, but there is still a need to overcome barriers, especially in a truly conceived winery. The wine industry faces the same challenge of implementing efficient systems as other industries do. 
Corresponding authors

Ing. Lucie Kan̆ovská, Ph.D.

Institute of Management, Faculty of Business and Management, Brno University of Technology

Kolejní 2906/4, Brno 612 00, Czech Republic

E-mail: kanovska@fbm.vutbr.cz

\section{References}

[1] Advanced Technologies for Industry (2017) "Smart vineyard: management and decision-making support for wine producers. Digital Transformation Monitor". [Online]. Available: https://ati. ec.europa.eu/sites/default/files/2020-06/Smart\%20vineyard-\%20management\%20and\%20decisionmaking\%20support $\% 20$ for $\% 20$ wine $\% 20$ producers $\% 20 \% 28$ v1\%29.pdf [Accessed: 20 Oct. 2020].

[2] Agdata (2020) "Vše pro chytré zemédělství v jednom systému". [Online]. Available: https://www. agdata.cz/ [Accessed: 10 Oct. 2020]. (In Czech).

[3] Bernetti, I., Casini, L. and Marinelli, N. (2006) "Wine and globalisation: changes in the international market structure and the position of Italy", British Food Journal, Vol. 108, No. 4, pp. 306-315. ISSN 0007-070X. DOI 10.1108/00070700610657146.

[4] Chytrá vinice (2020) “Jsme chytrá vinice“. [Online]. Available: https://sites.google.com/radekosicka. cz/jsme-chytra-vinice/home?authuser $=0$ [Accessed: 20 Aug. 2020]. (In Czech).

[5] CleverFarm.cz (2020) "Jsme průvodci chytrým a precizním zemédělstvi". [Online]. Available: https://www.cleverfarm.cz/o-nas [Accessed: 25 Aug. 2020]. (In Czech).

[6] Coleman, J. (1958) "Relational analysis: The study of social organizations with survey methods", Human organization, Vol. 17, No. 4, pp. 28-36. E-ISSN 1938-3525, ISSN 0018-7259. DOI 10.17730/humo.17.4.q5604m676260q8n7.

[7] Crookston, R. K. (2006) "A top 10 list of developments and issue impacting crop man-agement and ecology during the past 50 years", Crop Science, Vol. 46, No. 5, pp. 2253-2262. ISSN 1435-0653. DOI 10.2135/cropsci2005.11.0416gas.

[8] Cullen, R., Forbes, S. L. and Grout, R. (2013) "Non-Adoption of Environmental Innovations in Wine Growing", New Zealand Journal Crop Horticultural Science, Vol. 41, pp. 41-48. ISSN 01140671. DOI 10.1080/01140671.2012.744760.

[9] Dorofeeva, A. A., Kazak, A. N. and Nyurenberger, L. B. (2019) "Wine tourism and the introduction of new technologies in winemaking and viticulture", In IOP Conference Series: Earth and Environmental Science, Vol. 315, No. 7, IOP Publishing. DOI 10.1088/1755-1315/315/7/072040.

[10] Dressler, M. and Paunovic, I. (2020) "Converging and diverging business model innovation in regional intersectoral cooperation-exploring wine industry 4.0.", European Journal of Innovation Management, Vol. ahead-of-print No. ahead-of-print. ISSN 1460-1060. DOI 10.1108/EJIM-04-2020-0142.

[11] DYNACROP (2020) "Lightweight API with advanced satellite products for agriculture" [Online]. Available: https://dynacrop.space/en/about-dynacrop/ [Accessed: 18 Aug. 2020].

[12] EKOVÍN (2020) "Co je to ekologická produkce" [Online]. Available: http://www.ekovin.cz/ekovin/ sekce-ekologicke-produkce/co-je-to-ekologicka-produkce [Accessed: 20.10.2020]. ELKO EP (2020) "Chytré zemědělství. IoT ve službách zemědělství" [Online]. Available: https://www.elkoep. cz/media/files/download/item/files-332/11_Chytre_zemedelstvi_CZ_2019_print.pdf [Accessed: 10 Sept. 2020] (In Czech).

[13] Escolà, A, Camp, F, Solanelles, F, Calveras, J. L., de Martí S. P., Rosel, J. R., Gràcia, F. and Gil, E. (2007) "Variable dose rate sprayer prototype for tree crops based on sensor measured canopy characteristics", Proceedings of VI ECPA-European Conference on Precision Agriculture, June 3-6, Skiathos, Greece, pp. 563-571. ISBN 978908686024. 
[14] Gandhi, P., Somesh. K. and Sree R. (2016) "Which industries are the most digital (and why)". [Online]. Available: https://hbr.org/2016/04/a-chart-that-shows-which-industries-are-the-mostdigital-and-why [Accessed: 10 Aug. 2020].

[15] Giuliani, E., Morrison, A. and Rabellotti, R. (2011) "Innovation and technological catch-up: The changing geography of wine production", Edward Elgar Publishing, 232 p. ISBN 978184844994 7. DOI 10.1108/EJIM-04-2020-0142.

[16] Hallová, M., Polakovič, P. and Slováková, I. (2017) "Current Trends in Training of Managers in the Field of Information and Communication Technologies and Identifying the Barriers to Education of Managers", AGRIS On-line Papers in Economics and Informatics, Vol. 9, No. 4, pp. 45-52. ISSN 1804-1930. DOI 10.7160/aol.2017.090405.

[17] iNels (2020) "Smart pole, farma, louka i drůbežárna“. [Online]. Available: https://www.inels.cz/ smart-pole-farma-louka-i-drubezarna [Accessed: 20 Aug. 2020]. (In Czech).

[18] Kemper, E. A., Stringfield, S. and Teddlie, C. (2003) "Mixed methods sampling strategies in social science research", In Handbook of mixed methods in social and behavioral research, Thousand Oaks, CA: Sage. pp. 273-296.

[19] Kernecker, M., Knierim, A., Wurbs, A., Kraus, T. and Borges, F. (2020) "Experience versus expectation: farmers' perceptions of smart farming technologies for cropping systems across Europe", Precision Agriculture, Vol. 21, No. 1, pp. 34-50. ISSN 1385-2256. DOI 10.1007/s11119-019-09651-z.

[20] Knuth, U. and Knierim, A. (2016) "Interaction with and governance of increasingly pluralistic AKIS: a changing role for advisory services", Knowledge and Innovation Systems toward the Future, 104 p. [Online]. Available: https://scar-europe.org/images/AKIS/Documents/AKIS_foresight_ paper.pdf\#page=106 [Accessed: 19.9.2020]

[21] López-Leyva, J. A., Talamantes-Álvarez, A., Sanabia-Vincent, E., Aguilera-Silva, L., GastelumRodríguez, G. and Meza-Arballo, O. (2019) "Soil and environmental monitoring on a vineyard in the Guadalupe valley as a tool for processes of precision viticulture based on ZigBee technology to improve the e-agriculture", In International Conference on Smart Technologies, Systems and Applications, pp. 29-39. Springer, Cham. ISBN 978-3-030-46784-5. DOI 10.1007/978-3-030-46785-2_3.

[22] Maffioli, A., Ubfal, D., Vazquez-Bare, G. and Cerdan-Infantes, P. (2013) "Improving technology adoption in agriculture through extension services: evidence from Uruguay," Journal of Development Effectiveness, Vol. 5, No. 1, pp. 64-81. ISSN 1943-9342. DOI 10.1080/19439342.2013.764917.

[23] Matese, A., Toscano, P., Di Gennaro, S. F., Genesio, L., Vaccari, F. P., Primicerio, J., Belli, C., Zaldei, A., Bianconi, R. and Gioli, B. (2015) "Intercomparison of UAV, aircraft and satellite remote sensing platforms for precision viticulture", Remote Sensing, Vol. 7, No. 3, pp. 2971-2990. ISSN 2072-4292. DOI 10.3390/rs70302971.

[24] Matese, A. and Di Gennaro, S. F. (2015) "Technology in precision viticulture: A state of the art review", International Journal of Wine Research, Vol. 7, pp. 69-81. ISSN 1179-1403. DOI 10.2147/IJWR.S69405.

[25] Mariani, A., Pomarici, E. and Boatto, V. (2012) "The international wine trade: recent trends and critical issues", Wine Economics and Policy, Vol. 1, No. 1, pp. 24-40. ISSN 2212-9774. DOI 10.1016/j.wep.2012.10.001.

[26] Martini, B. G., Helfer, G. A., Barbosa, J. L., Modolo, R. C. E., da Silva M. R. and de Figueiredo, R. M. (2020) "Prediction and Context Awareness in Agriculture: A Systematic Mapping", AGRIS on-line Papers in Economics and Informatics, Vol. 12, No. 3, pp. 45-58. ISSN 1804-1930. DOI 10.7160/aol.2020.120305

[27] Nevyhoštěný, J. and Chripák, D. (2019) "Vínu letos hraji do not teploty, déšt' i slunce. Přicházi něco velkého, těši se vinaři“. [Online]. Available: https://zpravy.aktualne.cz/ekonomika/ceskaekonomika/vino-v-cesku-prehled-data-spotreba-podoblasti-odrudy-vinice/r $00 \mathrm{f} 4 \mathrm{c} 460 \mathrm{e} 1 \mathrm{a} 611 \mathrm{e} 88 \mathrm{~d} 4$ aac1f6b220ee8/ [Accessed: 20.8.2020] (In Czech). 
[28] Průžek, T. (2019) "Vinařství 4.0-1. část". [Online]. Available: https://www.prumysloveinzenyrstvi. cz/vinarstvi-4-0-1-cast/ [Accessed: 10 Sept. 2020]. (In Czech).

[29] Průžek, T. (2019) "Vinařství 4.0-2. část". [Online]. Available: https://www.prumysloveinzenyrstvi. cz/vinarstvi-4-0-2-cast/ [Accessed: 10 Sept. 2020]. (In Czech).

[30] Raddats, C., Kowalkowski, C., Benedettini, O., Burton, J. and Gebauer, H. (2019) "Servitization: A contemporary thematic review of four major research streams", Industrial Marketing Management, Vol. 83, pp. 207-223. ISSN 0019-8501. DOI 10.1016/j.indmarman.2019.03.015.

[31] Santesteban, L. G. (2019) "Precision viticulture and advanced analytics. A short review", Food chemistry, Vol. 279, pp. 58-62. ISSN 0308-8146. DOI 10.1016/j.foodchem.2018.11.140.

[32] Smart Akis (2020) "Smart Farming Thematic Network". [Online]. Available: https://www.smartakis.com/ [Accessed: 20 Aug. 2020].

[33] Proffitt, T. (2015) "Precision viticulture". [Online]. Available: https://www.evineyardapp.com/ blog/2015/09/16/use-of-technology-in-the-vineyard/ [Accessed: 20 Oct. 2020].

[34] Sneddon, J., Soutar, G. and Mazzarol, T. (2011) "Modelling the Faddish, Fashionable and Efficient Diffusion of Agricultural Technologies: A Case Study of the Diffusion of Wool Testing Technology in Australia", Technological Forecasting and Social Change, Vol. 78, pp. 468-480. ISSN 0040-1625. DOI 10.1016/j.techfore.2010.06.005.

[35] Spadoni, R., Nanetti, M., Bondanese, A. and Rivaroli, S. (2019) "Innovative solutions for the wine sector: The role of startups", Wine Economics and Policy, Vol. 8, No. 2, pp. 165-170. ISSN 2212-9774. DOI 10.1016/j.wep.2019.08.001.

[36] Srinivasan, A. (2006) "Handbook of precision agriculture. Principles and applications", New York; London; Oxford: Food Products Press. ISBN 9781560229551. DOI 10.1201/9781482277968.

[37] Strouhal, J. (2020) "Starý svět, nové technologie. Už i vinařum pomáhá umělá inteligence“. [Online]. Available: https://digibiz.cz/stary-svet-nove-technologie-uz-i-vinarum-pomaha-umela-inteligence/ [Accessed: 20 Aug. 2020]. (In Czech).

[38] Vieri, M., Sarri, D., Rimediotti, M., Perria, R. and Storchi P. (2013) "The new architecture in the vineyard system management for variable rate technologies and traceability", Acta Horticulturae, Vol. 978, pp. 47-53. ISBN 978-90-66052-09-3. ISSN 0567-7572. DOI 10.17660/ ActaHortic.2013.978.3.

[39] Vinařství roku (2020) "O projektu“. [Online]. Available: https://www.vinarstviroku.cz/\#o-projekty [Accessed: 20 Sept. 2020]. (In Czech).

[40] Voutos, Y., Mylonas, P., Spyrou, E. and Charou, E. (2018) "An IoT-based insular monitoring architecture for smart viticulture", In IEEE $20189^{\text {th }}$ International Conference on Information, Intelligence, Systems and Applications (IISA), pp. 1-4. DOI 10.1109/IISA.2018.8633630.

[41] Vrontis, D., Bresciani, S. and Giacosa, E. (2016) "Tradition and innovation in Italian wine family businesses", British Food Journal, Vol. 118, No. 8, pp. 1883-1897. ISSN 0007-070X. DOI 10.1108/BFJ-05-2016-0192.

[42] Wine regions of the Czech Republic (2020) "The Moravia Wine Region " [Online]. Available: https:// www.cmb-brno2020.cz/en/viticulture-in-cr/wine-regions/ [Accessed: 10 Sept. 2020].

[43] Yost, M. A., Kitchen, N. R., Sudduth, K. A., Sadler, E. J., Drummond, S. T. and Volkmann, M. R. (2017) "Long-term impact of a precision agriculture system on grain crop production", Precision Agriculture, Vol. 18, No. 5, pp. 823-842. ISSN 1385-2256. DOI 10.1007/s11119-016-9490-5. 